\title{
The Seven Deadly Tensions of Health-Related Human Information Behavior
}

\author{
J. David Johnson \\ University of Kentucky, Lexington, Kentucky, USA \\ jdi@uky.edu
}

\begin{abstract}
Tensions are a ubiquitous feature of social life and are manifested in a number of particular forms: contradictory logics, competing demands, clashes of ideas, contradictions, dialectics, irony, paradoxes, and/or dilemmas. This essay aims to explore in detail tensions surrounding seven common findings of the information seeking literature relating to: interpersonal communication, accessibility, level of skill, individual preferences, psychological limits, inertia, and costs. Our incomplete understanding of these tensions can lead us to suggest resolutions that do not recognize their underlying dualities. Human information behavior stands at the intersection of many important theoretical and policy issues (e.g., personalized medicine). Policy makers need to be more attuned to these basic tensions of information seeking recognizing the real human limits they represent to informing the public. So, even if you build a great information system, people will not necessarily use it because of the force of these underlying tensions. While rationality rules systems, irrationality rules people. The proliferation of navigator roles over the last several years is actually a hopeful sign: recognition that people need a human interface to inform them about our ever more complex health care systems.
\end{abstract}

Keywords: Human information behavior, health information seeking, tensions, paradoxes, dilemmas

\section{Introduction}

Wilson (2000, p. 49) defined information behavior as "the totality of human behavior in relation to sources and channels of information, including both active and passive information seeking and information use." A compelling feature of research on human information behavior (HIB) is that it stands at the intersection of so many important theoretical and policy issues such as the converging trends surrounding globalization and the 'flattening' of our world; the increasing complexity and blurring of boundaries represented by new organizational forms; the world of personalized medicine; and the intersection of technology and of human performance. These

Material published as part of this publication, either on-line or in print, is copyrighted by the Informing Science Institute. Permission to make digital or paper copy of part or all of these works for personal or classroom use is granted without fee provided that the copies are not made or distributed for profit or commercial advantage AND that copies 1) bear this notice in full and 2) give the full citation on the first page. It is permissible to abstract these works so long as credit is given. To copy in all other cases or to republish or to post on a server or to redistribute to lists requires specific permission and payment of a fee. Contact Publisher@,InformingScience.org to request redistribution permission. trends heighten the importance of tensions surrounding HIB. So, for example, organizations are designed to promote ignorance so that individuals can increase their understanding of particular issues through specialization.

This essay seeks to explore in detail tensions surrounding seven common findings revealed in several books that extensively review the information seeking literature relating to: interpersonal 
communication, accessibility, level of skill, individual preferences, psychological limits, inertia, and costs (Case, 2012; Johnson, 1996, 1997; Johnson \& Case, 2012). We need to deliberately confront the dilemmas and paradoxes embedded in these seven tensions if we are to accomplish our goal of informing the public.

\section{Tensions: Dilemmas and Paradoxes}

Tensions are a ubiquitous feature of social life. They are manifested in a number of particular forms: contradictory logics, competing demands, clashes of ideas, dialectics, irony, paradoxes, and/or dilemmas (Cooren, Matte, Benoit-Barne, \& Brummans, 2013). These tensions reveal contradictory and/or inconsistent qualities, statements that seem absurd but which may be true in fact. They stimulate us to deeper thought and a desire for resolution that needs to be approached deliberately. Dilemmas often represent a choice between equally balanced alternatives, each with associated costs and benefits, predicaments that seemingly defy a satisfactory resolution, often presented in either/or terms (Westenholz, 1993). We will explore tensions related to HIB to uncover their significance for the development of theory and policy.

Often our larger, normative cultural understandings prevent us from comprehending the true balance needed and the costs and benefits of potential resolutions of dilemmas. Indeed, our incomplete understanding can lead us to suggest resolutions that do not recognize the reality that some tensions are inherently paradoxical. Paradoxes are statements contrary to received opinion; seemingly contradictory statements that may nevertheless be true. "Paradox is the simultaneous existence of two inconsistent states, such as that between innovation and efficiency, collaboration and competition, or new and old" (Eisenhardt, 2000, p. 703). While paradoxes reveal seemingly contradictory elements of HIB, dilemmas often reveal contrasting forces that may represent opposing ends of an underlying continuum. They often entail either/or situations where one alternative must be selected, but they can also be paradoxical when options are contradictory and linked in such a way that any choice will only be a temporary one since tensions will resurface (Smith \& Lewis, 2011).

\section{The Seven Tensions}

Here we examine seven common findings, or empirical generalizations that reveal often deadly, or at least problematic, tensions that develop in HIB (see Table 1). These findings are distilled from reviews of over two thousand articles focusing on information seeking research drawn primarily from the disciplines of library and information science, communication, organizational theory, and health (Case, 2012; Johnson, 1996, 1997; Johnson \& Case, 2012).

\section{Interpersonal Communication}

Face-to-face, interpersonal communication is the preferred mode of communication for information seeking. It offers many compelling channel capabilities (Gill, 2008), including flexibility, feedback and subsequent message modification, greater relevance, a greater variety of rewards, and timeliness. It also is specific, vivid, and concrete, which generally is the kind of information decision makers prefer. People want to consult others who have digested and evaluated an array of written information that partially explains the role of surrogates, navigators, and intermediaries in most searches. Such interactivity is especially critical to e-health; people still want a human touch and often health impacts are dependent on it (Sundar, Rice, Kim, \& Sciamanna, 2011). Partly because of these advantages, face-to-face communication is more likely to be persuasive, especially when the source is a health professional (Lichter, 1987). Yet, face-to-face communication also has its liabilities, especially in terms of completeness, authoritativeness, and the lack of archiving of information. 
Table 1: Seven deadly tensions of human information behavior

\begin{tabular}{|l|l|}
\hline Tensions & \\
\hline $\begin{array}{l}\text { Interpersonal } \\
\text { communication }\end{array}$ & $\begin{array}{l}\text { In spite of their ubiquity and the breadth and depth available in other chan- } \\
\text { nels (e.g., the Internet), interpersonal communication, with all of its poten- } \\
\text { tial flaws, remains the overwhelming preference of information seekers. }\end{array}$ \\
\hline Accessibility & $\begin{array}{l}\text { Individuals knowingly seek out inferior information from a more accessible } \\
\text { source: accessibility outweighs quality }\end{array}$ \\
\hline Level of skill & $\begin{array}{l}\text { The more search experience we have, the more we are likely to search: the } \\
\text { rich get richer. }\end{array}$ \\
\hline limits & $\begin{array}{l}\text { The more information one has the less one is likely to understand it: more } \\
\text { information can result in greater ambiguity and uncertainty, not necessarily } \\
\text { improved decision making. }\end{array}$ \\
\hline Inertia & $\begin{array}{l}\text { People will rely on the old, tried and true sources even when they have giv- } \\
\text { en them bad information: the future is determined by the past. }\end{array}$ \\
\hline $\begin{array}{l}\text { Individual } \\
\text { preferences }\end{array}$ & $\begin{array}{l}\text { Professional training, taste, and aesthetic appeal outweigh the objective ca- } \\
\text { pabilities of information carriers. }\end{array}$ \\
\hline Costs & $\begin{array}{l}\text { The costs of knowing often outweigh its benefits and people tend to be } \\
\text { much more sensitive to the costs than to gains. }\end{array}$ \\
\hline
\end{tabular}

Individuals would prefer to turn to an individual whom they know and trust for information. Therefore, the quality of an individual's interpersonal networks has important implications for information seeking. In sum, in spite of enormous investments in the Internet and the seeming easy availability of a wealth of information, people still need people; regardless of the type of information needed, even for medical information, the first source they will consult is likely a friend or family member, posing an important dilemma for health professionals.

\section{Accessibility}

Another tension for policy makers is revealed in the common finding that people seek out information that is the most accessible; with their interpersonal networks playing a critical role as we have seen. Accessibility may be the most critical issue in designing information systems. What is most surprising is the threshold point where a source is considered inaccessible is very low. Similarly, somewhat disconcertingly, accessibility overrides such issues as the credibility and authoritativeness of a source. So, individuals will knowingly seek out inferior information from a more accessible source. Even when individuals need information they often do not actively, comprehensively search for it; rather they will wait until they accidentally stumble across the information, often in interpersonal encounters.

Accessibility outweighs quality in determining usage of information from sources (Johnson, 2009). For health policy makers, the timeliness of information and the problem it is to be applied to also often outweighs quality considerations. Interestingly, when consumers choose a physician, quality and competence are seldom considerations. In fact, it is a common finding that individuals will knowingly rely on inferior information sources for answers to their problems, because it would take too much effort to get authoritative information, even when it is easily available online (Sundar et al., 2011). However, even if we have access to 'facts', this does not mean we have the capacity to understand and successfully interpret them (Kent, 2001). 


\section{Level of Skill}

Interestingly, the more experience people have with a channel, the more accessible they perceive it to be. In turn, health professionals are more likely to recommend a wider range of sources to patients they think can engage with and make sense of them (Lewis, Gray, Freres, \& Hornik, 2009). People who get information on the Internet are more likely to seek information from health professionals to make sense of (interpret) and make use of the information (Lee, 2008). In this version of a virtuous cycle, the more one has the more one is likely to get exacerbating the digital divide that has long concerned HIB professionals.

Having access to information means very little if an individual does not have the proper information seeking skills and training to retrieve it or the health literacy to understand it. A recent HHS report found that only $12 \%$ of the American populace are proficient in information literacy (Health and Human Services, 2010) with literacy often interacting with other disparities to limit the benefits of health information technology to only the best connected segments of our population (Miller \& West, 2009). Seekers are often unaware of sources and how to use them. Especially at the beginning of a search, users are often in a state of flux without clear criteria and with the search proceeding in a dynamic fashion, with values of information and sources changing as it proceeds. In their early stages, searches can be characterized by the gathering of bits and pieces that an individual can fit into a coherent whole. So, skill and literacy often determine if one will search and the quality of answers one obtains. Acquiring information is a necessary, not a sufficient condition; one must also know what to with it.

\section{Psychological Limits}

There are cognitive limits on the amount of information individuals can process, especially in short-term memory. Miller's classic observation that we can only viably keep seven things in mind at any one time establishes an absolute barrier to information processing (Mintzberg, 1975). Beyond this absolute limit, the presence of additional information, especially in overload conditions, such as patients experience when first diagnosed with cancer, lowers even this limited capacity. While it has become a truism that knowing how to search for information should be a major focus of our educational systems, rather than imparting perishable knowledge, the limits on short-term memory suggest having a sound and deep knowledge base is critical to decision making and that, especially for information for responding to time critical events like heart attacks and strokes, this information should be 'front-loaded' since there is not time enough to conduct an external search.

Beyond the limits of memory, humans have a limited ability to process and interpret information. Decision making is fraught with incomplete data gathering, shortcuts, errors, and biases. Decision makers group stimuli into existing broad category schemes which leads them not to search for additional information. They consistently tend to a confirmation bias, ignoring or discounting disconfirming evidence. They often ignore their existing base of information (the base-rate fallacy) and will focus on compelling new information. For example, chronically ill patients may be subject to fads associated with new treatments. They also engage in the sample size fallacy, generalizing from very limited experience. So, if a new treatment has met with success with one member of a support group, others may assume that it will meet with similar success with all patients. At best, humans are limited in their capacity to seek, process, and correctly interpret information (Jamieson \& Hyland, 2006). Even more importantly, they often are not aware of their limitations, grossly overstating their accuracy in information processing tasks, for example, and, interestingly, in some cases, they are happiest when overloaded even when they know this leads them to make flawed decisions (O'Reilly, 1980). Disturbing biases in search engines (e.g., favoring a positive perspective; biases of systems to prior searchers focus on exotic, devastating diseases; larger proportions of information relating to serious illnesses versus benign conditions; 
escalatory terminology) can interact with the tensions revealed in biases in searchers' decision making (e.g., preference for positive information, base rate fallacies, availability bias, confirmation bias) to increase searchers' anxiety (White \& Horvitz, 2009); to lead them settle on incorrect answers around half of the time; and to increase the demand for medical services (White, 2009, 2013).

\section{Inertia}

People follow habitual patterns in their information seeking. They fall into a pattern of information seeking on particular topics. The information they have previously acquired promotes efforts to acquire additional information, which suggests that the critical first step in facilitating information seeking is encouraging a habit for it. Unfortunately, most people have bad information seeking habits and there is considerable inertia that must be overcome in changing their existing behaviors. At times, interpersonal channels can compel one to overcome inertia - nagging surrogates and intermediaries; but, it is more likely that they will support our preexisting frameworks.

Direct experience has somewhat of an insidious side effect, since once someone is familiar with a source they tend to continue to use it. Interestingly, almost two-thirds of respondents to a survey said they would return to an information source even when they had characterized it in the least helpful category (Johnson \& Case, 2012).

The tensions surrounding inertia are exacerbated by the number of competing sources of information available on any one subject. Most individuals find, partly because of time pressures, that they cannot engage in a comprehensive search for information. Given that there may be twenty sources of information available and they are familiar with two, and they trust these two based on prior experience, there may be little perceived benefit to consulting any one of the remaining eighteen.

The dark side of the quest for uncertainty reduction is that, once an answer is arrived at and a decision made, blockage from future information seeking may occur (Smithson, 1989). Or, stated in a different way, local search and reuse of existing knowledge results in rigidity, while expanding the scope of the search introduces the new, but also may introduce unreliability (Katila \& Ahuja, 2002). The Law of Abandoned Expertise suggests "[c]lients will resist any task-related informing activities that require relinquishing existing expertise in their problem space" (Gill, 2008, p. 296). Disastrous consequences often arise from situations where group ideas become accepted as truth, discouraging even the possibility of seeking discordant information. How long do we hold on to an answer we struggled so hard to attain? The more skillful and knowledgeable one is, the less likely they are to acquire useful novel information. Because of competency traps, people are reluctant to give up the familiar even when the new is likely to be superior; they are reluctant to drop the tools they took so much trouble to master.

\section{Individual Preferences}

Different types of persons use different sources of information. Usually the more experienced, educated, and knowledgeable the individual, the wider the array of information sources they have access to and are likely to consult. Beyond such broad generalizations, however, are the different patterns of searches that have become accepted as 'standard practice' in various professions. The particular 'profile' of any one individual seeker may reflect the unique informal norms and socialization practices of a particular profession. One of the key differentiators of professions is how they go about seeking and their standards for truth (e.g., journalist's law of two corroborating sources and physicians adhering to a standard of care principle). Professional standards some- 
times trump interpersonal channels, but doctors still rely heavily on interpersonal contacts for understanding new treatment options and adopting them (Johnson, 2012).

Of course, additional sources of information add confidence in a course of action if they corroborate each other. But, if the sources do not provide consistent answers, a not unlikely circumstance, then someone has complicated his/her decision making. In fact, more communication can result in greater ambiguity and uncertainty, not improved decision making (Rice \& Shook, 1990). While inconsistent information may often be a spur for additional information seeking to find a 'tie breaking' source, there is no guarantee that this additional source of information will not present yet another major alternative. So, it becomes easier to understand why there might be real benefits, at least in terms of the amount of effort expended, to consulting only a limited range of familiar sources thus reducing tensions.

\section{Costs}

All of the forgoing findings are related to the 'costs' of information seeking compared to the value or benefit of the information sought, particularly in relation to decision making. The costs of information acquisition are many - psychological, temporal, and material. Most seekers appear to assume it is better to rely on easily obtained information (they have an answer after all) no matter how dubious, than to spend the effort necessary to get complete information. The 'costs' in terms of extra time and effort for a complete information search, which also may result in delaying opportunities, complicating decision making, and increasing information overload, are real. There are also additional psychological costs, such as the loss of self-esteem and frustration that result from an unsuccessful search, which may lead to individuals totally rejecting the use of some sources of information they are frustrated with. One of the few conditions when interpersonal is not preferred is when its use may involve loss of status or face (Johnson, 2009) with stigma associated with certain diseases often limiting the use of some social media (de Choudhury, Morris, \& White, 2014).

These costs have been articulated in various 'laws' of information seeking behavior. The classic law of 'least effort' has been evoked to articulate why channels are chosen first that involve the least effort: Mooer's Law suggests an information source or system will tend not to be used whenever it is more painful and troublesome to have the information than it is not to have it. Beyond these generalizations, lies the basic assumption that people desire to know (Johnson \& Case, 2012).

Ignorance is only one of many problems an individual has to confront. At times it is better to rely on easily obtained information than to spend the effort necessary to seek complete information. In short, the costs of overcoming ignorance at times outweigh the gains. (And what is astounding is how low the costs are that determine absolute barriers to information seeking.) It is even possible, at least for particular topics, to be sated, to have acquired enough information. Thus, there may be as many, if not more, reasons for not seeking as for seeking.

The ultimate goals of rationality may be to develop a sense of coherence, and a simple one at that, with satisficing the standard rather than maximizing. While more and more information can be produced more efficiently, there is a concomitant increase in the costs of consuming (e.g., interpreting, analyzing) this information. Fundamentally we must accept human limits to information processing and match our efforts to the task at hand to achieve the ideal level for decision making that balance the various tensions involved.

Traditionally, the behavioral decision school of organizational theory argued the primary impetus for information gathering was in supporting decision making. Theorizing in this area increasingly moved away from a strictly rational approach to an appreciation for uncertainty and the very human limits in processing an ever increasing volume of information (Gill, 2008; Jamieson \& 
Hyland, 2006). In the process, people came to a greater appreciation of the dilemmas posed by decision making and the need to balance various competing tensions: to simultaneously attend to many competing problems leads to satisficing and an increasing realization of the limits that make 'perfect' decision making unlikely.

\section{Implications}

If you build a great information system, people will not necessarily use it. Policy makers need to be more attuned to these basic tensions of HIB recognizing the real human limits they represent. One viable strategy, of course, would be to conduct training programs that increase individuals' awareness of sources, how to use them, and for what they are appropriate. There is evidence that individual information processing can be substantially enhanced by holding positions that demand higher levels of processing (Zajonc \& Wolfe, 1966) and by long experience in professional roles. So, somewhat akin to chess masters who can instantly react to complex patterns based on experience, professionals develop an intuitive feel for how to react to complex information patterns. For example, one key advantage of physicians as a source is in the level of intuition and reasoning ability they have developed as result of their training and long experience which deepens their tacit understandings of medical issues.

\section{Practice Implications}

Information seeking involves the purposive acquisition of information by clients which models such as the Single Client Resonance Model then suggest is mediated by filters that in turn determine decision processes and ultimately decision outcomes (Gill, 2008). These filters, informational, cognitive, risk, and uncertainty reduction (Jamieson \& Hyland, 2006), also impact the processes of information seeking, which in some cases is a precursor to decision processes, as in non-programmed decision making, to the ones involved in making ultimate decisions. So cost tensions, with people more concerned with losses than gains (Gill, 2008) in the seeking process, can interact with these filters in various ways increasing the probability of biased or limited searches. Ultimately HIB and the resolution of the tensions described earlier determines the information a client has secured on their own that they will ultimately use in decision making.

Paradoxically, the first step to resolving tensions may be to accept them; they are inevitable features of life (Cameron \& Quinn, 1988). Indeed, specifying resolutions in and of itself may be paradoxical, since a focus on dilemmas involves a recognition that there really may not be any hope of resolving them. So, often tensions are managed by just 'muddling through' (Cooren et al., 2013). The point may not be some grand synthesis, resolution, but mindful recognition of tensions and resulting contradictions. Our contemporary world in some ways represents a perfect storm for HIB. The convergence of technologies, the flood of information, and institutional changes in the professions challenging us to recognize the underlying tensions focused on here. It is dangerous to rely on our assumptions of what should be done based on a rational, one dimensional view of HIB.

Information seeking research, which adopts a receiver rather than a sender perspective, suggests that rational, persistent approaches to channel selection are seldom used by individuals when they actually seek health information (Johnson \& Case, 2012). However, when a client is actively involved in their own information seeking, highly motivated to secure an answer to their perceived needs, and they have commensurate level of self-efficacy, they are more likely to comply with any information they uncover, with the outcomes of information searches in effect becoming teachable moments (Johnson \& Case, 2012). The client is seeking messages that resonate with their needs and that will stick (Gill, 2008). The key is to get someone started down the road, because as we have seen once they start momentum builds (Miller \& West, 2009), but unfortunately so does the availability information. In that sense we are fighting a losing battle, the pace at 
which the available knowledge increases far exceeds the innate capacity of individuals to keep up.

Are professionals keeping up with their changing roles? Are institutions meeting the challenge? Are practitioners charged with informing clients aware of these tensions? Is everyone being overwhelmed? HIB is a moving target, there is also a possibility for retrogression - people's level of ignorance has not really changed in spite of technological growth and increased access (Mohammed, 2012). With the amount one needs to know increasing with every passing day, the gap between what one needs to know and what they do know in relative terms actually may be growing.

\section{Conclusion}

Being forced to choose between unpleasant, disagreeable, unfavorable tensions in HIB is often very difficult, but the important thing is that we be conscious of them so that we are clear as to their costs and benefits, since there are often unintended consequences when we unconsciously tilt in one direction (e.g., rational information systems). Sometimes, as in Eastern religion's concepts of yin/yang, it is better to accept the presence of a two-sided coin and relish the interplay between them (Gupta, Smith, \& Shalley, 2006) rather than maximize one at the expense of the other. For example, one must often reconcile divergent points of view in a hospital's strategic planning (Meyer, 1984). Constantly favoring doctors, who often hold the moral high ground over accountants, might quickly land a hospital into bankruptcy.

Unfortunately, because they are often masked by their seemingly irrational behavior, the seven tensions are often ignored by policy makers and system designers. While rationality rules systems, irrationality rules people. The proliferation of navigator roles over the last several years is actually a hopeful sign: recognition that people need a human interface to keep them informed of our ever more complex health care systems.

\section{References}

Cameron, K. S., \& Quinn, R. E. (1988). Organizational paradox and transformation. In R. E. Quinn \& K. S. Cameron (Eds.), Paradox and transformation: Toward a theory of change in organizations and management (pp. 1-18). Cambridge, MA: Ballinger.

Case, D. O. (2012). Looking for information (3rd ed.). Bingley, UK: Emerald Group Publishing.

Cooren, F., Matte, F., Benoit-Barne, C., \& Brummans, B. H. J. M. (2013). Communication as ventroloquism: A grounded-in-action approach to the study of organizational tensions. Communication Monographs, 80(3), 255-277.

de Choudhury, M., Morris, M. R., \& White, R. W. (2014). Seeking and sharing health information online: Comparing search engines and social media. Paper presented at the ADM SIGCHI Conference on Human Factors in Computing Systems, Toronto, ON.

Eisenhardt, K. M. (2000). Paradox, spirals, ambivalence: The new language of change and pluralism. Academy of Management Review, 25, 703-705.

Gill, T. G. (2008). The single client resonance model: Beyond rigor and relevance. Informing Science: The International Journal of an Emerging Discipline, 11, 281-310. Retrieved from http://inform.nu/Articles/Vol11/ISJv11p281-310Gill222.pdf

Gupta, A. K., Smith, K. G., \& Shalley, C. E. (2006). The interplay between exploration and exploitation. Academy of Management Journal, 49, 693-706.

Health and Human Services. (2010). National Action Plan to Improve Health Literacy. Retrieved from http://www.health.gov/communication/HLActionPlan/pdf/Health_Lit_Action_Plan_Summary.pdf. 
Jamieson, K., \& Hyland, P. (2006). Good intuition or fear and uncertainty: The effects of bias on information system selection decisions. Informing Science Journal, 9, 49-69. Retrieved from http://inform.nu/Articles/Vol9/v9p049-069Jamieson60.pdf

Johnson, J. D. (1996). Information seeking: An organizational dilemma. Westport, CT: Quorom Books.

Johnson, J. D. (1997). Cancer-related information seeking. Cresskill, NJ: Hampton Press.

Johnson, J. D. (2009). Managing knowledge networks. Cambridge, UK: Cambridge University Press.

Johnson, J. D. (2012). The role of human agents in facilitating clinical and translational science. Clinical and Translational Science, 5(4), 353-361. doi: 10.1111/j.1752-8062.2011.00379.x

Johnson, J. D., \& Case, D. O. (2012). Health information seeking. New York: Peter Lang.

Katila, R., \& Ahuja, G. (2002). Something old, something new: A longitudinal study of search behavior and new product introduction. Academy of Management Journal, 45, 1183-1194.

Kent, M. L. (2001). Managerial rhetoric as the metaphor for the world wide web. Crticial Studies in Media Communication, 18(3), 359-375.

Lee, C. (2008). Does the internet displace health professionals? Journal of Health Communication, 13, 450464. doi: 10.1080/10810730802198839

Lewis, N., Gray, S. W., Freres, D. R., \& Hornik, R. C. (2009). Examining cross-source engagement with cancer-related information and its impact on doctor-patient relationships. Health Communication, 24, 723-734. doi: 10.1080/10410230903274030

Lichter, I. (1987). Communication in cancer care. New York: Churchill Livingstone.

Meyer, A. D. (1984). Mingling decision making metaphors. Academy of Management Review, 9, 6-17.

Miller, E. A., \& West, D. M. (2009). Where's the revolution? Digital technology and health care in the internet age. Journal of Health Politics, Policy and Law, 34(2), 261-284. doi: 10.1215/03616878-2008046

Mintzberg, H. (1975). Impediments to the use of management information. New York: National Association of Accountants.

Mohammed, S. N. (2012). The (dis)information age. New York: Peter Lang.

O'Reilly, C. A., III. (1980). Individuals and information overload in organizations: Is more necessarily better? Academy of Management Journal, 23, 684-696.

Rice, R. E., \& Shook, D. E. (1990). Relationships of job categories and organizational levels to use of communication channels, including electronic model: A meta-analysis and extension. Journal of Management Studies, 27, 196-229.

Smith, W. K., \& Lewis, M. W. (2011). Toward a theory of paradox: A dynamic equilibrium model of organizing. Academy of Management Review, 36(2), 381-403.

Smithson, M. (1989). Ignorance and uncertainty: Emerging paradigms. New York: Springer-Verlag.

Sundar, S. S., Rice, R. E., Kim, H., \& Sciamanna, C. N. (2011). Online health information: Conceptual challenges and theoretical opportunities. In T. L. Thompson, R. Parrott, \& J. F. Nussbaum (Eds.), The Routledge handbook of health communication (2nd ed., pp. 181-202). New York: Routledge.

Westenholz, A. (1993). Paradoxical thinking and change in frame of reference. Organization Studies, 14, 37-58.

White, R. W. (2009). Experiences with web search on medical concerns and self diagnosis. Paper presented at the AMIA Annual Symposium.

White, R. W. (2013). Beliefs and biases in web search. Paper presented at the SIGIR'13: Conference on Research and Development in Information Retrieval, Dublin, Ireland. 
White, R. W., \& Horvitz, E. (2009). Cyberchondria: Studies of the escalation of medical concerns in web search. ACM Transactions in Information Systems, 27(4). doi: 10.1145/1629096.1629101

Wilson, T. D. (2000). Human information behavior. Informing Science, 3, 49-55. Retrieved from https://www.ischool.utexas.edu/ i385e/readings/Wilson.pdf

Zajonc, R. B., \& Wolfe, D. M. (1966). Cognitive consequences of a person's position in a formal organization. Human Relations, 19, 139-150.

\section{Biography}

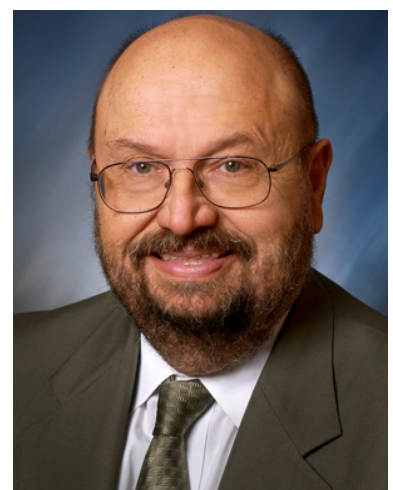

J. David Johnson (PhD, Michigan State University, 1978) was Dean of the College of Communications and Information Studies at the University of Kentucky for over a decade. He is currently a Professor in the Department of Communication. He has published eight books: most recently Health Information Seeking with Donald Case. He has been recognized as among the one-hundred most prolific publishers of refereed journal articles in the communication discipline. He has worked in an advisory capacity for state and federal agencies in the field of health, most recently on the Communication Expert Panel for the Centers for Disease Control Office of Smoking and Health, Health Communications Branch 